\title{
ARTIGO
}

CO https://doi.org/10.22481/praxisedu.v16i37.6175

\section{REACHING CONSENSUS: A SCOPING REVIEW ON SCHOOL-BASED COMPREHENSIVE SEXUALITY EDUCATION PROGRAMS (CSE)}

\author{
ALCANZAR EL CONSENSO: UNA REVISIÓN DE ALCANCE SOBRE LOS \\ PROGRAMAS DE EDUCACIÓN INTEGRAL EN SEXUALIDAD (CSE) BASADOS EN \\ LA ESCUELA
}

\begin{abstract}
CHEGAR A UM CONSENSO: UMA REVISÃO DO ESCOPO DOS PROGRAMAS ABRANGENTES DE EDUCAÇÃO EM SEXUALIDADE (CSE) NAS ESCOLAS
\end{abstract}

Keshvar Samadaee Gelehkolaee

Tehran University of Medical Sciences - Iran

Seyed Ali Azin

Avicenna Research Institute - Iran

Saharnaz Nedjat

Tehran University of Medical Sciences - Iran

Arshia Zamani Hajiabadi

Mazandaran University of Medical Sciences - Iran

Raziyeh Maasoumi

Tehran University of Medical Sciences - Iran

\begin{abstract}
Sexuality education in schools is a hot topic in part because it is closely intertwined with social and parental interpretations of right and wrong. This study is a scoping review that was conducted in six steps: (1) identification of the research question, (2) identification of relevant studies, (3) selection of studies, (4) data extraction, (5) summarizing and reporting the results, and (6) consultation with stakeholders. Curricula were assessed by the Curriculum Evaluation Tool (SIECUS) and guidelines were evaluated by the appraisal of guidelines for research \& evaluation (AGREE II) tool. After reviewing 24 programs extracted from 50 studies, the majority of which $(90 \%)$ were designed and utilized in developing countries, 5 questions were answered. Finally, the "Guidelines for the Sexual Health education component of Comprehensive Health Education" guideline, and the "FLEHI, WSWM, Tuko Pamoja" curricula were recommended with modifications. This review shows that CSE programs are not only cost-effective interventions, but also part of adolescents' sexual rights. At the beginning of
\end{abstract}


the program, there may be many social and cultural barriers in developing countries, but once a rigorous culturally based program is designed successful results can be achieved. Therefore, designing such programs based on the Iranian culture is strongly recommended.

Keywords: Scoping review, Comprehensive Sexuality Education, School-based, Youth.

Resumen: La educación sexual en las escuelas es un tema candente en parte porque está estrechamente entrelazado con las interpretaciones sociales y parentales de lo correcto y lo incorrecto. Este estudio es una revisión de alcance que se realizó en seis pasos: (1) identificación de la pregunta de investigación, (2) identificación de estudios relevantes, (3) selección de estudios, (4) extracción de datos, (5) resumen e informe resultados, y (6) consulta con las partes interesadas. Los currículos se evaluaron mediante la Herramienta de evaluación curricular (SIECUS) y las directrices se evaluaron mediante la evaluación de las directrices para la herramienta de investigación y evaluación (AGREE II). Después de revisar 24 programas extraídos de 50 estudios, la mayoría de los cuales (90\%) fueron diseñados y utilizados en países en desarrollo, se respondieron 5 preguntas. Finalmente, se recomendaron con modificaciones las pautas de "Pautas para el componente de educación en salud sexual de la educación integral en salud" y los planes de estudio "FLEHI, WSWM, Tuko Pamoja". Esta revisión muestra que los programas de CSE no son solo intervenciones rentables, sino también parte de los derechos sexuales de los adolescentes. Al comienzo del programa, puede haber muchas barreras sociales y culturales en los países en desarrollo, pero una vez que se diseña un programa riguroso de base cultural, se pueden lograr resultados exitosos. Por lo tanto, se recomienda encarecidamente diseñar tales programas basados en la cultura iraní.

Palabras clave: revisión del alcance, educación integral en sexualidad, escolar, juventud.

Resumo: A educação sexual nas escolas é um tema quente em parte porque está intimamente entrelaçada com interpretações sociais e parentais do certo e do errado. Este estudo é uma revisão de escopo que foi conduzida em seis etapas: (1) identificação da questão de pesquisa, (2) identificação de estudos relevantes, (3) seleção de estudos, (4) extração de dados, (5) resumo e relatório da (6) consulta com as partes interessadas. Os currículos foram avaliados pela Ferramenta de Avaliação de Currículo (SIECUS) e as diretrizes foram avaliadas pela avaliação das diretrizes para a ferramenta de pesquisa e avaliação (AGREE II). Após a revisão de 24 programas extraídos de 50 estudos, a maioria dos quais (90\%) foram projetados e utilizados em países em desenvolvimento, cinco perguntas foram respondidas. Finalmente, as diretrizes "Diretrizes para o componente de educação em saúde sexual da Educação Integral em Saúde" e os currículos "FLEHI, WSWM, Tuko Pamoja" foram recomendados com modificações. Esta análise mostra que os programas de CSE não são apenas intervenções de baixo custo, mas também fazem parte dos direitos sexuais dos adolescentes. No início do programa, pode haver muitas barreiras sociais e culturais nos países em desenvolvimento, mas uma vez que um programa cultural rigoroso é projetado, resultados bem-sucedidos podem ser alcançados. Portanto, é altamente recomendável projetar esses programas com base na cultura iraniana.

Palavras-chave: Revisão do escopo, Educação Integral em Sexualidade, Base escolar, Juventude.

\section{Introduction}

The sex education debate worldwide takes on special relevance because sex and its related health outcomes are a reality in the lives of many young people (Collins, Alagiri, 
Summers, \& Morin, 2002). Most adolescents have been in school for many years before they initiate sex (nearly $95 \%$ of all youth aged 5 to 17 years are enrolled in elementary or secondary schools) and when they do, schools have the potential to reduce high risk adolescent sexual behavior (D. Kirby, 2002). Sexuality education in schools is a hot topic in part because it is closely intertwined with social and parental interpretations of right and wrong, and with people's feelings about religion and personal autonomy. Yet, it is also intended to serve a variety of practical public health purposes - to reduce STIs, violence, and unwanted pregnancy among young people (Roy, Roy, \& Rangari, 2007).

There are many educational approaches in this field, most of which are divided into two categories, including comprehensive sex education (or 'abstinence-plus') and 'abstinenceonly-until-marriage'. Much of the debate has centered on whether abstinence-only versus comprehensive sexuality education programs (CSE) should be taught in public schools (Stanger-Hall \& Hall, 2011). School-based comprehensive health education is designed for students to develop life skills, so they can make informed and responsible decisions in life (Huaynoca, Chandra-Mouli, Yaqub Jr, \& Denno, 2014). Therefore, it's important to know which programs can help improve adolescent sexual health. ("Adolescent Health Research Priorities: Report of a Technical Consultation. Geneva: World Health Organization. 2015,"). Studies have argued about the benefits of CSE against abstinence-only education (Collins et al., 2002; D. B. Kirby, 2008; Stanger-Hall \& Hall, 2011). Based on these studies, there is little evidence on abstinence programs to warrant their widespread application; conversely, there is strong evidence to support that some CSEs should be widely disseminated (D. B. Kirby, 2008). To achieve the educational goals set by the Iranian government, the curriculum should be strategically formulated into certain programs because the curriculum is important and part of the educational program. Therefore, the assessment and selection of health education programs in any school district should be based on clearly identified goals, health needs, health behavior expectations (cultural and religious norms), and outcomes for health education ("https://www.cdc.gov/healthyschools/professional_development/e-learning/hecat.html,"; Information \& States, 2004). However, there is a paucity of systematic appraisals of the existing programs focused on adolescent sexual health. 


\section{Methods}

Scoping review is an ideal methodology for mapping key concepts within a research area, identifying the main sources and types of evidence available, and identifying gaps in the existing research (Lima et al., 2017). This scoping review was developed using the scoping review methodological framework proposed by Levac et al (Levac, Colquhoun, \& O'Brien, 2010). It was conducted in six steps: (1) identification of the research question, (2) identification of relevant studies, (3) selection of studies, (4) data extraction, (5) summarizing and reporting the results and (6) consultation with stakeholders (optional) (Levac et al., 2010; Lima et al., 2017).

\section{Stage 1: Identification of the research question}

The PICO strategy (P: population, I: intervention, C: comparison, O: outcomes) was used to write the research questions, as the first stage of the study is the conception of one or more research questions. Medical Subject Headings Terminology (MESH) was used to select the keywords, with 'P' being the population (Adolescence, Teenagers, Youths), 'I' intervention (Curricula, Course, Module, Protocols, Guideline, Educational programs, Directory) and 'o' the outcome (sexual health, risk reduction, harm reduction) (Samadaee-Gelehkolaee et al., 2016).

\section{Stage 2: Identifying relevant studies}

At this stage, the research team established the inclusion and exclusion criteria, electronic databases.

\section{Inclusion and exclusion criteria}

Inclusion criteria: All the accessible articles published in English and Persian on school-based education programs that had evaluated and improved adolescent sexual health were included without a time limit.

Exclusion criteria: Sexual education programs that weren't comprehensive and schoolbased and that did not cover the age of 10-19 years were excluded. 


\section{Databases}

The researchers used the following resources to identify relevant studies: World Health Organization (WHO), Center For Disease Control and Prevention (CDC), Medical Institute for Sexual Health (MISH), Sexuality Information and Education Council of the United States (SIECUS), Connecticut State Department of Education (CSDE), Action Health Incorporated (AHI), Web of Science; The Cochrane Library, the Scientific Electronic Library Online (SciELO), MEDical Literature Analysis and Retrieval System Online (PubMed/MEDLINE), Google Scholar's general search engine, and then more specifically, Science Direct, ProQuest, SID, Magiran, Scopus, and Cumulative Index to Nursing and Allied Health Literature (CINAHL).

\section{Stage 3: Study selection}

The review process consisted of two levels of screening: (1) title and abstract review, and (2) full-text review. The criteria were determined based on the consensus reached by the research team. Studies that were deemed relevant by either or both reviewers were included in the full-text review. In the second step, the two investigators independently assessed the fulltext studies to determine if they met the inclusion/exclusion criteria or not (Lima et al., 2017). Scoping reviews do not allow studies to be excluded according to methodological quality criteria; thus, the items included in this review were not submitted to an evaluation of methodological quality (Lima et al., 2017). Studies describing the implementation of sexual health programs for adolescents in school or the community were included. Finally, 26 studies were selected to examine the most important educational indicators and administrative capability. Thereafter, the curricula were evaluated by the Curriculum Evaluation Tool (SIECUS) ${ }^{1}$. The Health Education Curriculum Evaluation Tool (HECAT) is an assessment tool that examines the main health issues taught at school by educational policy makers and teachers. (Information \& States, 2004). This tool consists of eight parts: concepts and topics covering abstinence and safer sex, fear or shame-based messages, accuracy and relevance, teaching strategies, cultural sensitivity, parental involvement, other considerations and a STIs/HIV checklist. Each section of the key concepts is subdivided into subgroups. In the key

\footnotetext{
${ }^{1}$ Sexuality Information and Education Council of the United States (SIECUS)
} 
concepts section, each concept is graded according to its emphasis. A score of 1 indicates 'major emphasis' and a score of 5 means 'not addressed'. When parts 1, 3, and 6 gain lower scores they indicate a better status (Information \& States, 2004) (Table 1).

Table 1. Assessing Curriculum based on the Curriculum Evaluation Tool (SIECUS)

\begin{tabular}{|c|c|c|c|c|c|c|c|c|}
\hline \multicolumn{2}{|c|}{ Curriculum characteristics } & IRAN* & SHAER & FLEHI & WSWM & LLL & DAKU & Tuko Pamoja \\
\hline \multirow{6}{*}{ 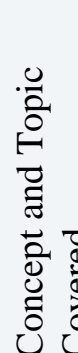 } & Human Development & 16 & 10 & 6 & 6 & 6 & 6 & 6 \\
\hline & Relationship & 12 & 6 & 6 & 6 & 6 & 6 & 6 \\
\hline & Personal Skills & 10 & 10 & 6 & 6 & 6 & 6 & 6 \\
\hline & Sexual Behavior & 24 & 12 & 8 & 11 & 13 & 15 & 10 \\
\hline & Sexual Health & 20 & 7 & 7 & 7 & 9 & 8 & 7 \\
\hline & Society and Culture & 19 & 10 & 7 & 10 & 8 & 8 & 9 \\
\hline \multicolumn{2}{|c|}{ Abstinence and Safer Sex } & $25 \%$ & $90 \%$ & $95 \%$ & $100 \%$ & $100 \%$ & $100 \%$ & $100 \%$ \\
\hline \multicolumn{2}{|c|}{ Fear or Shame-based Messages } & $70 \%$ & $20 \%$ & $10 \%$ & $2 \%$ & $0 \%$ & $4 \%$ & $2 \%$ \\
\hline \multicolumn{2}{|c|}{ Accuracy and Relevance } & $60 \%$ & $100 \%$ & $100 \%$ & $100 \%$ & $100 \%$ & $100 \%$ & $100 \%$ \\
\hline \multicolumn{2}{|c|}{ Teaching Strategies } & $80 \%$ & $98 \%$ & $99 \%$ & $100 \%$ & $100 \%$ & $100 \%$ & $100 \%$ \\
\hline \multicolumn{2}{|c|}{ Cultural Sensitivity } & $50 \%$ & $25 \%$ & $25 \%$ & $25 \%$ & $25 \%$ & $25 \%$ & $25 \%$ \\
\hline \multicolumn{2}{|c|}{ Parental Involvement } & $25 \%$ & $95 \%$ & $100 \%$ & $100 \%$ & $100 \%$ & $100 \%$ & $100 \%$ \\
\hline \multicolumn{2}{|c|}{ Other Consideration } & $60 \%$ & $99 \%$ & $100 \%$ & $100 \%$ & $100 \%$ & $97 \%$ & $100 \%$ \\
\hline \multicolumn{2}{|c|}{ STDs/HIV Checklist } & $20 \%$ & $97 \%$ & $97 \%$ & $99 \%$ & $98 \%$ & $98 \%$ & $100 \%$ \\
\hline
\end{tabular}

* Comprehensive curriculum for health education in schools.

Guidelines were evaluated by the 'appraisal of guidelines for research \& evaluation' tool (AGREE II). The AGREE instrument is a tool used for evaluating the methodological quality of guidelines (Consortium, 2009). This tool contains 23 items comprising 6 quality domains. The domain scores were calculated by adding up the scores of the items in each domain and calculating the total of the maximum possible score obtainable for each domain.

This study was conducted by three separate appraisers for each guideline. The total score of all three appraisers was collected for each individual domain (Obtained score).

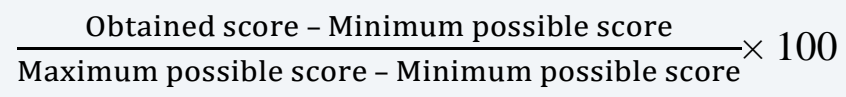

Finally, the appraisers provided two evaluations of the guideline. They determined the quality of the guideline based on the assessment criteria and determined whether or not they could recommend the guideline for their setting (Consortium, 2009) (Table 2). 
Table 2. Assessing Guidelines based on the appraisal of guidelines (AGREE II)

\begin{tabular}{|l|l|l|l|l|l|l|}
\hline Guideline Name & $\begin{array}{l}\text { domain 1 } \\
\text { score }\end{array}$ & $\begin{array}{l}\text { domain 2 } \\
\text { score }\end{array}$ & $\begin{array}{l}\text { domain 3 } \\
\text { score }\end{array}$ & $\begin{array}{l}\text { domain 4 } \\
\text { score }\end{array}$ & $\begin{array}{l}\text { domain 5 } \\
\text { score }\end{array}$ & $\begin{array}{l}\text { domain 6 } \\
\text { score }\end{array}$ \\
\hline $\begin{array}{l}\text { 1. International technical guidance on } \\
\text { sexuality education }\end{array}$ & $100 \%$ & $100 \%$ & $83 \%$ & $92 \%$ & $90 \%$ & $100 \%$ \\
\hline $\begin{array}{l}\text { 2. Guidelines for the Sexual Health } \\
\text { education component of Comprehensive } \\
\text { Health Education }\end{array}$ & $100 \%$ & $100 \%$ & $95 \%$ & $98 \%$ & $94 \%$ & $100 \%$ \\
\hline $\begin{array}{l}\text { 3. Guidelines for Comprehensive } \\
\text { Sexuality Education }\end{array}$ & $83 \%$ & $92 \%$ & $81 \%$ & $90 \%$ & $80 \%$ & $100 \%$ \\
\hline
\end{tabular}

\section{Stage 4: Data collection}

Data extracted from studies based on the objectives of the study were categorized in response to five questions: 1. What are the key concepts of a CSE program? 2. What are the characteristics of an effective program? 3. What are the opportunities and threats of performing a CSE program? 4. What do we need for CSE programs in developing countries? 5. What achievements have CSE programs gained till now?

\section{Stage 5: Summarizing and reporting the results}

In this scoping review, we examined 24 programs out of 50 studies to answer the questions in Step 4. The results of this study have been described in the tables.

\section{Stage 6: A consultation exercise}

According to Levac et al, this step provides an opportunity for stakeholders to become involved and provides a more expanded vision in comparison to what has been highlighted in the literature (11). Therefore, we conducted the study in 4 steps, as follows: 1) We prepared a summary of the needs, challenges, barriers and solutions; 2) We prepared a list of questions based on the review of studies and conducted individual in-depth interviews via semi-structured with the stakeholders including teachers, directors, policy makers, counselors and adolescents; 3) We transcribed the interviews and extracted the codes; and finally, 4) We concluded that curriculums should be localized by the educational and medical specialists of each country and tailored to their adolescent community's needs. Furthermore, given the sensitivity of the 
context, it is essential to work on changing stakeholders' attitudes, including those of parents, teachers and policy makers before the implementation of the curriculum.

\section{Results}

Upon examining the databases a total number of 50 studies were identified, within which 24 programs were found. Ten of these programs met the inclusion criteria. Thereafter, three guidelines and seven curricula were evaluated (see in Table 1,2). The programs were mostly (80\%) intra-curricular and approximately $90 \%$ of them had been designed and utilized in developing countries. Eventually, the 'Guidelines for the Sexual Health education component of Comprehensive Health Education' and 'FLEHI, WSWM, Tuko Pamoja' were selected from the guidelines and curricula, respectively, and were recommended with certain modifications. Finally, based on the similarities of the programs, we answered the following 5 questions:

Question 1: What are the key concepts of a CSE program?

Based on users' needs and country-specific characteristics, such as the epidemiological context and cultural norms, topics were based on learning objectives that could be adjusted for inclusion within different age groups (UNFPA, 2014). Eight key concepts were included: 1) Personal relationships, 2)Rights, values, culture and sexuality,3)Gender conception,4)Violence and safety,5)Skills for well-being and a healthy life, 6)Human development, 7)Sexual behavior and sexuality,8)Sexual and health $(\mathrm{SRH})$

("https://portal.ct.gov/SDE/Publications/Sexual-Health-Education-Component-of-

Comprehensive-Health-Education/Overview-of-Sexual-Health-Education,"

"https://portal.ct.gov/SDE/Publications/Sexual-Health-Education-Component-of-

Comprehensive-Health-Education/Sexual-Health-Education-Curriculum-Framework," "https://www.cdc.gov/healthyyouth/hecat/index.htm," ; Women \& UNICEF, 2018)

Question 2: What are the characteristics of an effective program for sexual health? 1. Attention to health goals and related behavioral consequences, 2. Is evidence-based, age-appropriate and theory-driven, 3. Involves young people, parents and other community stakeholders,4. Assesses the resources (human, financial and time) available, 5. Assesses the social, SRH needs and behaviors of the target group, 6. Improve people's life skills, 7. Addresses risk and protective factors that affect sexual behaviors, 8. Provides scientifically accurate information about 
sexually transmitted infections, contraception, unintended pregnancy and the effectiveness and availability of different services and methods of protection, 9. Provides all sexual orientations and identities with information beyond bias and discrimination, 10. Addresses the management of specific situations that might lead to violence and request for help (Berkowitz \& Bier, 2007; Haruna, Hu, \& Chu, 2018; D. Kirby \& Laris, 2009; Women \& UNICEF, 2018).

Question 3: What are the opportunities and threats of performing CSE programs in developing countries?

Threats: 1. Lack of knowledge and the society's misconceptions of adolescents sexual education; 2. Health policymakers have a political or religious attitude and approach toward sexual health issues; 3 . There is a large gap between the current situation and the society's expectations of adolescents; 4. Lack of social and political support for implementation of adolescents sexual health program; 5. Lack of youth-friendly services in public sectors; 6 . Discussing sex and sexuality in the community is a taboo; 7. Lack of teachers' knowledge and skills (Chandra-Mouli, Plesons, Hadi, Baig, \& Lang, 2018; Huaynoca et al., 2014; UNFPA, 2014; Wight \& Buston, 2003).

Opportunities: 1. The availability of successful guidelines and curricula; 2. The WHO, UNFPA, IPPF and UNAIDS are committed to supporting countries to apply the Guidelines that help countries realize young people's right to education, well-being, and to achieve an inclusive and gender-equal society in order to achieve the Sustainable Development Goals (SDGs); 3. Research on adolescent health was introduced as a research priority by the WHO; 4. There are large numbers of students attending schools. (Initiative, 2012; Organization, 2017; UNFPA, 2014; Women \& UNICEF, 2018).

Question 4: Why do we need CSE programs in developing countries?

Education is an important topic globally, as it is one of the human rights principles that can help us achieve sustainable development (Information \& States, 2004). The lifelong CSE program can be formalized in most low- and middle- income countries where STIs are common and impose great burden on their economy (Fonner, Armstrong, Kennedy, O'Reilly, \& Sweat, 2014; Information \& States, 2004). Among the sex-related problems in developing countries, high teenager pregnancy rates, STIs and sexual violence stand out (Chandra-Mouli et al., 2018; Huaynoca et al., 2014). Offering free widespread education in such countries can lower poverty, child and maternal mortality rates and lead to economic growth (Chin et al., 2012; Kivela, 
Ketting, \& Baltussen, 2013). Therefor adolescents' needs for information and reproductive health services due to changes in gender roles, marriage age and social norms were increased (Farahani, Shah, Cleland, \& Mohammadi, 2012; Sajjadi, Moshki, Abasnezhad, \& Bahri, 2012; Zare, Simbar, Shahhosseini, \& Alavi Majd, 2017a).

Question 5: What achievements have CSE programs gained until now?

Kivela et al believe that the implementation of sexual education programs in schools led to remarkable improvements in sexual health indicators in the 15-24 age group in Estonia between 2001 and 2009 (Kivela, Haldre, Part, Ketting, \& Baltussen, 2014). To support the claim that this program has been cost-effective another study was conducted on six countries that indicated a reduction in health costs per person; costs per student reached were, US\$13.50 in India, US\$50 in Kenya, US\$160 in Indonesia, US\$7 in Nigeria and US\$33 in Estonia and the Netherlands (Kivela et al., 2013). Although there are concerns that CSE may increase sexual risk-taking behavior, studies clearly show that sexuality education programs do not increase sexual risk-taking. On the contrary, evidence suggests that CSE has positive impacts and that it improves knowledge and attitudes about different aspects of sexuality (Aarø et al., 2014; Mathews et al., 2012; Wight \& Buston, 2003; Wolfe et al., 2009).

\section{Discussion}

Despite the significantly positive effects of the sexual education programs introduced across Europe in 1982 (Berne, Huberman, \& Alford, 1999), very little is known about the patterns and trends of its implementation across its conservative countries. In countries like Nigeria, Indonesia, Pakistan and Iran, sexuality education is a sensitive issue. The latter has significant consequences for the method with which CSE programs can be offered (CSE versus abstinence-only). The selection of this educational approach affects the costs and has potential impact on the sense of well-being (Stanger-Hall \& Hall, 2011; Udegbe et al., 2015). This study therefore represents an attempt to address the gap in the implementation of CSE programs in Iran.

Policymakers involved in decision-making about sexuality education programs face three important questions (Kivela et al., 2013): What are the target group's SRH needs? Studies have confirmed that intra-curricular -as opposed to extra-curricular- sex education programs have a greater capacity for being reinforced and are thus more effective (Kivela et al., 2014; 
Kivela et al., 2013). The majority of these programs have a noticeable effect on the improvement of sexual behaviors (D. B. Kirby, Laris, \& Rolleri, 2007; Women \& UNICEF, 2018). Adolescent sexual health needs have been identified by several studies (Farahani et al., 2012; Mohammadi et al., 2006; Zare, Simbar, Shahhosseini, \& Alavi Majd, 2017b). Therefore, health policy makers need to design strategies that help meet adolescents' health needs. Subsequently, we reviewed the strengths and weaknesses of the guidelines based on Kivela's recommendations, that "new initiatives save costs by adapting existing programs to their own (social and cultural) context, instead of developing new ones between manuals and educational programs" (Kivela et al., 2013). All the studies agree on the principles and key concepts, but the International technical guidance (Women \& UNICEF, 2018) and sexual health education component （"https://portal.ct.gov/.../Sexual-Health...Health.../Sexual-Health-EducationCurriculum-Framework,") seem to lay greater emphasis on specific populations (disabled people, variety of sexual orientations), focusing on evaluation strategies and also supported by great agencies and their information is up-to-date, so they can be recommended.

In developing countries like Iran, social and cultural barriers have hindered sexual education in schools. A comprehensive health education curriculum is available but not up-todate and compliant with sexual health education standards ("www.behdasht.gov.ir/index.aspx?siteid=1\&pageid=156.,"). Among high-risk behaviors, this curriculum lays emphasis on addiction and AIDS (as the only problem among sexuallytransmitted infections). It also seems that its educational approach is 'abstinence-only-untilmarriage'. In this study, six curricula called WSWM ${ }^{2}$ ("https://www.rutgers.international/what-we-do/comprehensive-sexuality-education/depthworld-starts-me,"), $\quad$ SHARE $^{3} \quad$ ("https://www.washoeschools.net/Page/10551,"), FLEHI ("http://www.actionhealthinc.org/publication/. ,"), LLL5(Schutte et al., 2014), Tuko Pamoja (Behague, Christenson, Martin, Wysong, \& Kibusu, 2006) and DAKU were evaluated. Not only do these curricula contain the essential topics listed in the guidance and framework of sexual education ("https://portal.ct.gov/search-results/?q=Healthy and Balanced Living Curriculum Framework,"), but their effectiveness has also been confirmed by various studies (Huaynoca et al., 2014; Kivela et al., 2014; Rijsdijk et al., 2011; Wight \& Buston, 2003). Therefore, these curricula can be recommended with certain modifications. Although the LLL

\footnotetext{
${ }^{2}$ The World Starts With Me (WSWM).

${ }^{3}$ Sexuality, Health And Responsibility Education (SHARE).

${ }^{4}$ Family Life and Emerging Health Issues (FLEHI).

${ }^{5}$ Long Live Love (LLL).
} 
curriculum has gained good scores in its evaluation and its cost-effectiveness has been confirmed by various studies (Apter, 2011; Kivela et al., 2013; Schutte et al., 2014), it is not recommended for developing countries like Iran, due to its cultural discrepancies.

\section{Conclusion}

Based on this scoping review and the insights provided by the interviews on sexuality education programs, six key principle steps were identified for their establishment:

1. Clarify the programs' objectives and the roles of different players and ensure local/national ownership/leadership; 2. Choose educational approaches that can be implemented within existing systems; 3. Identify the perceived needs of the target groups and adapt them to existing political systems; 4 . Examine the effectiveness and cost-effectiveness of existing training programs; 5. Adapt existing programs to social and cultural norms; 6. Pilot programs before execution.

There are invaluable programs for building professional capacity in the field of adolescent sexual health. These programs are not only cost-effective interventions for adolescents, but also part of their human rights.

\section{Acknowledgements}

This study is part of a larger study (Ph.D. thesis: Design, pilot implementation and assessment of a context based program on male adolescents' sexual health special for instructors: a multi-stage study) that is supported by the Tehran University of Medical Sciences in 2018 with a code of ethics IR.TUMS. FNM.REC.1397.102.

\section{REFERENCES}

1. Aarø, L. E., Mathews, C., Kaaya, S., Katahoire, A. R., Onya, H., Abraham, C., . . . De Vries, H. (2014). Promoting sexual and reproductive health among adolescents in southern and eastern Africa (PREPARE): project design and conceptual framework. BMC public health, 14(1), 54. 
2. Adolescent Health Research Priorities: Report of a Technical Consultation. Geneva: World Health Organization. 2015.

3. Apter, D. (2011). Recent developments and consequences of sexuality education in Finland. Paper presented at the FORUM Sexuality Education and Family Planning.

4. Behague, S., Christenson, K., Martin, S., Wysong, M., \& Kibusu, K. (2006). Tuko Pamoja: adolescent reproductive health and life skills curriculum.

5. Berkowitz, M. W., \& Bier, M. C. (2007). What works in character education. Journal of Research in Character Education, 5(1), 29.

6. Berne, L., Huberman, B., \& Alford, S. (1999). European approaches to adolescent sexual behavior and responsibility: executive summary and call to action. Washington, DC: Advocates for Youth.

7. Chandra-Mouli, V., Plesons, M., Hadi, S., Baig, Q., \& Lang, I. (2018). Building support for adolescent sexuality and reproductive health education and responding to resistance in conservative contexts: Cases from Pakistan. Global Health: Science and Practice, 6(1), 128-136.

8. Chin, H. B., Sipe, T. A., Elder, R., Mercer, S. L., Chattopadhyay, S. K., Jacob, V., . . Griffith, M. (2012). The effectiveness of group-based comprehensive risk-reduction and abstinence education interventions to prevent or reduce the risk of adolescent pregnancy, human immunodeficiency virus, and sexually transmitted infections: two systematic reviews for the Guide to Community Preventive Services. American journal of preventive medicine, 42(3), 272-294.

9. Collins, C., Alagiri, P., Summers, T., \& Morin, S. F. (2002). Abstinence only vs. comprehensive sex education: What are the arguments? What is the evidence?

10. Consortium, A. N. S. (2009). Appraisal of guidelines for research and evaluation II instrument. Retrieved May, 12, 2011.

11. Farahani, F. K. A., Shah, I., Cleland, J., \& Mohammadi, M. R. (2012). Adolescent males and young females in Tehran: differing perspectives, behaviors and needs for reproductive health and implications for gender sensitive interventions. Journal of Reproduction \& Infertility, 13(2), 101.

12. Fonner, V. A., Armstrong, K. S., Kennedy, C. E., O'Reilly, K. R., \& Sweat, M. D. (2014). School Based Sex Education and HIV Prevention in Low- and Middle-Income Countries: A Systematic Review and Meta-Analysis. PloS one, 9(3), e89692. doi: 10.1371/journal.pone.0089692

13. Haruna, H., Hu, X., \& Chu, S. K. W. (2018). Adolescent School-Based Sexual Health Education and Training: A Literature Review on Teaching and Learning Strategies. Glob. J. Health Sci, 10, 172. http://www.actionhealthinc.org/publication/. . https://portal.ct.gov/.../SexualHealth...Health.../Sexual-Health-Education- Curriculum-Framework.

14. Huaynoca, S., Chandra-Mouli, V., Yaqub Jr, N., \& Denno, D. M. (2014). Scaling up comprehensive sexuality education in Nigeria: from national policy to nationwide application. Sex Education, 14(2), 191-209. doi: 10.1080/14681811.2013.856292

15. Information, S., \& States, E. C. o. t. U. (2004). Guidelines for comprehensive sexuality education: Kindergarten-12th grade: Author New York.

16. Initiative, F. o. S. E. (2012). National sexuality education standards: Core content and skills, K12 [a special publication of the Journal of School Health]. Retrieved May 232014 from.

17. Kirby, D. (2002). The impact of schools and school programs upon adolescent sexual behavior. Journal of sex research, 39(1), 27-33. 
18. Kirby, D., \& Laris, B. (2009). Effective curriculum-based sex and STD/HIV education programs for adolescents. Child Development Perspectives, 3(1), 21-29.

19. Kirby, D. B. (2008). The impact of abstinence and comprehensive sex and STD/HIV education programs on adolescent sexual behavior. Sexuality Research \& Social Policy, 5(3), 18.

20. Kirby, D. B., Laris, B., \& Rolleri, L. A. (2007). Sex and HIV education programs: their impact on sexual behaviors of young people throughout the world. Journal of Adolescent Health, 40(3), 206-217.

21. Kivela, J., Haldre, K., Part, K., Ketting, E., \& Baltussen, R. (2014). Impact and costeffectiveness analysis of the national school-based sexuality education programme in Estonia. Sex Education, 14(1), 1-13.

22. Kivela, J., Ketting, E., \& Baltussen, R. (2013). Cost analysis of school-based sexuality education programs in six countries. Cost effectiveness and resource allocation, 11(1), 17.

23. Levac, D., Colquhoun, H., \& O'Brien, K. K. (2010). Scoping studies: advancing the methodology. Implementation science, 5(1), 69.

24. Lima, D. K. S., Schoeller, S. D., da Silva Knihs, N., Vargas, C. P., Tholl, A. D., Lopes, S. G. R., . . de Almeida Hammerschmidt, K. S. (2017). Protocol for a scoping review of skin selfcare of people with spinal cord injury. BMJ open, 7(9), e017860.

25. Mathews, C., Aarø, L., Grimsrud, A., Flisher, A., Kaaya, S., Onya, H., . . Klepp, K.-I. (2012). Effects of the SATZ teacher-led school HIV prevention programmes on adolescent sexual behaviour: cluster randomised controlled trials in three sub-Saharan African sites. International Health, 4(2), 111-122.

26. Mohammadi, M. R., Mohammad, K., Farahani, F. K., Alikhani, S., Zare, M., Tehrani, F. R., . . . Alaeddini, F. (2006). Reproductive knowledge, attitudes and behavior among adolescent males in Tehran, Iran. International family planning perspectives, 35-44.

27. Organization, W. H. (2017). Adolescent health research priorities: report of a technical consultation, WHO reference number: WHO: FWC/MCA/15/07.

28. Rijsdijk, L. E., Bos, A. E., Ruiter, R. A., Leerlooijer, J. N., de Haas, B., \& Schaalma, H. P. (2011). The World Starts With Me: A multilevel evaluation of a comprehensive sex education programme targeting adolescents in Uganda. BMC public health, 11(1), 334.

29. Roy, S., Roy, S., \& Rangari, K. (2007). Comprehensive health care including sexual and reproductive health of adolescents and youths is of vital importance to the nation. Health and Population-Perspectives and Issues, 30(4), 243-267.

30. Sajjadi, M., Moshki, M., Abasnezhad, A., \& Bahri, N. (2012). Educational needs of fathers about boys puberty period and its related factors. Zahedan Journal of Research in Medical Sciences, 14(2), 66-70.

31. Samadaee-Gelehkolaee, K., McCarthy, B. W., Khalilian, A., Hamzehgardeshi, Z., Peyvandi, S., Elyasi, F., \& Shahidi, M. (2016). Factors Associated With Marital Satisfaction in Infertile Couple: A Comprehensive Literature Review. Global journal of health science, 8(5), 96.

32. Schutte, L., Meertens, R. M., Mevissen, F. E., Schaalma, H., Meijer, S., \& Kok, G. (2014). Long Live Love. The implementation of a school-based sex-education program in the Netherlands. Health education research, 29(4), 583-597.

33. Stanger-Hall, K. F., \& Hall, D. W. (2011). Abstinence-only education and teen pregnancy rates: why we need comprehensive sex education in the US. PloS one, 6(10), e24658.

34. Udegbe, B. I., Fayehun, F., Isiugo-Abanihe, U. C., Nwagwu, W., Isiugo-Abanihe, I., \& Nwokocha, E. (2015). Evaluation of the implementation of family life and HIV education programme in Nigeria. African journal of reproductive health, 19(2), 79-92. 
35. UNFPA. (2014). Operational Guidance for Comprehensive Sexuality Education: A Focus on Human Rights and Gender: UNFPA New York.

36. Wight, D., \& Buston, K. (2003). Meeting needs but not changing goals: evaluation of in-service teacher training for sex education. Oxford Review of Education, 29(4), 521-543.

37. Wolfe, D. A., Crooks, C., Jaffe, P., Chiodo, D., Hughes, R., Ellis, W., . . Donner, A. (2009). A school-based program to prevent adolescent dating violence: A cluster randomized trial. Archives of pediatrics \& adolescent medicine, 163(8), 692-699.

38. Women, U., \& UNICEF. (2018). International technical guidance on sexuality education: an evidence-informed approach: UNESCO Publishing.

39. www.behdasht.gov.ir/index.asp $x$ ?siteid $=1$ \&pageid $=156$.

40. Zare, E., Simbar, M., Shahhosseini, Z., \& Alavi Majd, H. (2017a). The Priorities of Iranian Male Adolescents Health Needs. American Journal of Men's Health, 1557988317693346.

41. Zare, E., Simbar, M., Shahhosseini, Z., \& Alavi Majd, H. (2017b). The Priorities of Iranian Male Adolescents Health Needs. American Journal of Men's Health, 11(4), 1255-1259.

\section{SOBRE OS AUTORES:}

\section{Keshvar Samadaee Gelehkolaee}

PhD Student in Reproductive Health, Department of Reproductive Health, School of Nursing and Midwifery, Tehran University of Medical Sciences, Tehran, Iran. E-mail: moshaversamadai@yahoo.com

(iD) http://orcid.org/0000-0002-9692-187X

\section{Seyed Ali Azin}

Associate professor, Reproductive Biotechnology Research Center, Avicenna Research Institute (ACECR), Tehran, Iran. E-mail: saliazin@ gmail.com

(iD) http://orcid.org/0000-0002-3629-0869

\section{Saharnaz Nedjat}

Full professor, Department of Epidemiology and Biostatistics, Tehran University of Medical Sciences, Tehran, Iran. E-mail: nejatsan@tums.ac.ir

(iD http://orcid.org/0000-0002-0966-727X

\section{Arshia Zamani Hajiabadi}

Medical Student, Student research committee, Faculty of medicine, Mazandaran University of Medical Sciences, Sari, Iran.E-mail: arshiazamani1378@gmail.com

(iD) http://orcid.org/0000-0001-7422-5892 


\section{Raziyeh Maasoumi}

Assistant Professor, Nursing and Midwifery Care Research Center, School of Nursing and Midwifery, Tehran University of Medical Sciences, Tehran, Iran. Post.doc of Sexology, PhD of Reproductive Health, Department of Reproductive Health, Nursing and Midwifery Care Research Center, School of Nursing and Midwifery, Tehran University of Medical Sciences, Tehran, Iran. Corresponding author: r_masoumi@sina.tums.ac.ir

(iD http://orcid.org/0000-0002-4986-4104 